\title{
A formação de professores e a capacitação de bibliotecários com limitação visual por meio da EAD em ambiente virtual de aprendizagem
}

\author{
Teachers formation and visual disabled librarians training through \\ e-learning in learning virtual environment
}

Lizandra Brasil ESTABEL'

Eliane Lourdes da Silva MORO2

Lucila Maria Costi SANTAROSA ${ }^{3}$

\section{RESUMO}

Esta pesquisa aborda o uso e a apropriação das Tecnologias de Informação e de Comunicação (TICs) pelas Pessoas com Necessidades Educacionais Especiais (PNEEs) com limitação visual e os processos de interação e de aprendizagem por esses sujeitos em um ambiente virtual de aprendizagem (AVA). O cenário desta pesquisa é o AVA TelEduc e as suas ferramentas, bem como as ferramentas de comunicação e de interação externas ao ambiente, como o MsChat e o Skype. Fazem parte deste processo quatro sujeitos com limitação visual (SB, AL, NO e AM), professores e bibliotecários dos cursos PROINESP, da Secretaria de Educação Especial do Ministério da Educação (SEESP/MEC), em parceria com a Universidade Federal do Rio Grande do Sul (UFRGS), por meio do Núcleo de Informática na Educação Especial (NIEE) e do BIBLIOTEC II, Curso de Extensão em Bibliotecas Escolares e Acessibilidade, do Departamento de Ciências da Informação da Faculdade de Biblioteconomia e Comunicação (DCI/FABICO), da UFRGS. O problema de pesquisa pretende verificar como ocorre, na formação a distância em Ambientes Virtuais de Aprendizagem, o processo de apropriação e de interação, no uso das Tecnologias de Informação e de Comunicação, de professores e de bibliotecários com limitação visual. Dentre os objetivos, destacam-se os de propiciar a formação e a qualificação a distância de professores e bibliotecários com limitação visual, por meio de AVA e avaliar os processos de apropriação, de interação e a inclusão social, digital e profissional. A epistemologia vygotskyana foi a base desta pesquisa e a linha mestra do processo pedagógico. A partir das análises realizadas dos processos de apropriação e de interação dos sujeitos desta pesquisa, pode-se concluir que SB, AL, NO e AM conseguiram apropriar-se das ferramentas e serem mediadores deste processo de apropriação pelos seus alunos e interagiram entre eles (sujeitos), com os colegas, com os formadores e com os alunos por meio do uso das ferramentas, sendo incluídos em um ambiente virtual de aprendizagem.

Palavras-chave: ambientes virtuais de aprendizagem; pessoas com necessidades educacionais especiais com limitação visual; formação de professores; capacitação de bibliotecários.

\footnotetext{
1 Doutora em Informática. Pesquisadora, Núcleo de Informática na Educação Especial (NIEE), Universidade Federal do Rio Grande do Sul (UFRGS). Av Paulo Gama, Prédio 12201, Sala 308, 90046-900, Porto Alegre, RS, Brasil. Correspondência para/Correspondece to: L..B. ESTABEL. E-mail: <liz.estabel@gmail.com>.

2 Doutoranda em Educação, PPGEDU/UFRGS. Professora, Curso de Biblioteconomia, FABICO/UFRGS, Pesquisadora do Núcleo de Informática na Educação Especial (NIEE/UFRGS). Porto Alegre, RS, Brasil. E-mail: <eliane moro@yahoo.com.br>.

3 Professora Doutora, PPGEDU e do PGIE/UFRGS, Coordenadora Nacional da RIBIE e do PROINESP/MEC, Coordenadora do Núcleo de Informática na Educação Especial (NIEE/UFRGS). Porto Alegre, RS, Brasil. E-mail: <lucila.santarosa@ufrgs.br>. Recebido em 1/3/2008 e aceito para publicação em 7/11/2008.
} 


\begin{abstract}
This research approaches the use and the appropriation of ICTs, by PNEEs with visual disability and their interaction and learning processes in an AVA. The background of this research is AVA TelEduc and their tools, as well as the external tools to the environment: MsChat and Skype. Four visual disabled people are part of this process (SB, AL, $N O$ and $A M)$, as well as PROINESP courses teachers and librarians. The research main goal is to verify how the appropriation and interaction process in the use of ICTs happens in long distance educational system - AVAs -, among teachers and librarians with visual disability. Among the objectives, stand out to provide long distance graduation and qualification through AVA to teachers and librarians with visual disability, and to evaluate appropriation and interaction processes as well as the social, digital and professional inclusion. The Vygotskyan epistemology was the foundation for this research. Starting from the accomplished analyses of the appropriation and interaction processes of the involved people in this research, it can be settled that $S B, A L, N O$ and $A M$ were able to appropriate themselves of the tools and be mediators of the appropriation process to their students. They also interacted among themselves, among friends, teachers and students by using the tools and by being included in a virtual-learning environment.
\end{abstract}

Keywords: virtual environments for Learning; people with special educational needs with visual disability; teachers training; librarians long distance education.

\section{INTRODUÇÃO}

Surgem novas concepções sobre o papel que a escola representa na sociedade: precisa ser um espaço inclusivo, que atenda as diversidades e que propicie uma educação de qualidade, apresentando respostas às necessidades de seus educandos. $O$ aluno é o centro desse processo e a escola inclusiva deve estar preparada para propiciar a cooperação e a solidariedade, por meio do respeito e da valorização das diferenças, oportunizando uma educação para todos e a inclusão social, digital, informacional, educacional e profissional das Pessoas com Necessidades Educacionais Especiais (PNEEs).

As PNEEs com limitação visual, ao longo da história humana, ficaram por muito tempo afastadas da cultura letrada. $\bigcirc$ acesso à informação ocorria na oralidade, dificultando a sua formação e inclusão na sociedade, devido à dependência de outra pessoa para ter acesso ao meio cultural.

Para Vygotsky (2003, p.260)

"o princípio fundamental da educação dos cegos é o método da concepção social de seu defeito.
Acredita-se que se pode propiciar às PNEEs com limitação visual condições de acesso à educação, à aprendizagem e ao desenvolvimento da mesma forma que às pessoas com visão normal. Ambientes de aprendizagem como a sala de aula e a biblioteca devem oferecer condições para o aprendizado, o desenvolvimento e a interação com os seus pares. A apropriação e o uso das Tecnologias de Informação e de Comunicação (TICs) são a possibilidade de inclusão das PNEEs no cenário educacional. Por meio da Educação Aberta e a Distância (EAD) e do uso de Ambientes Virtuais de Aprendizagem (AVAs) pode-se formar professores e qualificar bibliotecários com limitação visual para atuarem com mais segurança, qualidade e competência nos ambientes de aprendizagem.

O processo de interação entre os sujeitos e destes com as ferramentas pode propiciar às PNEEs com limitação visual a superação das suas limitações. Diante do exposto, a pesquisa realizada busca responder ao seguinte questionamento: de que forma se dá a apropriação e o uso das TICs em EAD, o acesso ao ambiente virtual de aprendizagem, o processo de mediação, pelos professores e bibliotecários com limitação visual, e a sua inclusão social, digital e profissional? Pretende-se por meio desta pesquisa responder a esse questionamento de forma a contribuir para uma nova possibilidade de inclusão das pessoas com limitação visual na sociedade, a partir da epistemologia vygotskyana. 


\section{A EPISTEMOLOGIA VYGOTSKYANA E AS PESSOAS COM NECESSIDADES EDUCACIONAIS ESPECIAIS COM LIMITAÇÃO VISUAL}

Para Vygotsky (1997), em sua obra sobre defectologia, volume 5, a tese central da defectologia atual é que todo defeito cria os estímulos para elaborar uma compensação. Afirma que, como para a Medicina moderna o importante não é a enfermidade, senão o enfermo, para a defectologia o objeto não se constitui na insuficiência em si, senão a criança envolvida pela insuficiência. Anteriormente se supunha que toda a vida da criança cega e todo seu desenvolvimento se estruturariam segundo a linha da cegueira; a lei atual diz que o desenvolvimento irá ao contrário dessa linha. Se há cegueira, o desenvolvimento psíquico está orientado em direção oposta à cegueira, contra a cegueira.

Vygotsky (1997) afirma que seria errôneo supor que o processo de compensação sempre termina em êxito e conduz à formação do talento a partir do defeito. Como qualquer processo de superação e de luta, também a compensação pode ter dois desenlaces extremos: a vitória e a derrota, entre os quais se situam todos os graus possíveis de transição de um pólo a outro. O desenvolvimento agravado por um defeito constitui um processo (orgânico e psicológico) de criação e recriação da personalidade da criança, sobre a base da organização de todas as funções de adaptação, da formação de novos processos superestruturados, substitutivos, niveladores, que são gerados pelo defeito, e da abertura de novos caminhos ao redor do desenvolvimento. "Un mundo de formas y vías nuevas de desarollo, ilimitadamente diversas se abre ante la defectología. La línea defecto-compensación es precisamente la linea directriz del desarollo del niño con el defecto de algún órgano o función". (Vygotsky, 1997, p. 16-17).

A criança cega ou surda desenvolve-se como a criança sem deficiência, porém, de modo diferente, percorre caminhos diferentes, com outros meios, e para o professor é importante conhecer a peculiaridade do caminho pelo qual conduzirá o educando. $\bigcirc$ autor era contra a escola para "tontos" ou escola especial, afirmando que influi até sobre a auto-estima dos professores, colocando-os em uma espécie de lugar inferior em comparação com os professores de escolas regulares. "Ir a uma 'escuela para tontos' significa para el niño estar en una difícil posición social". Para o autor, "tanto el desarollo como la educación del niño ciego no tienen tanta relación con la ceguera en si misma, como con las consecuencias sociales de la ceguera". (Vygotsky, 1997, p.17-19). Novas perspectivas se abrem ante o professor quando ele passa a acreditar que a deficiência pode ser também uma força e, em certo sentido, positiva. "En esta oposición entre la deficiencia orgánicamente y los deseos, fantasías, sueños, es decir las tendencias psíquicas a la compensación están implícitas el punto de partida e las fuerzas motrices de toda educación." (Nygotsky, 1997, p.46).

Vygotsky (1997) declara que a humanidade sempre sonhou com um milagre religioso: que os cegos enxergassem e que os surdos ouvissem. É provável que a humanidade triunfe um dia sobre a cegueira, a surdez e a deficiência mental, porém as vencerá no plano social e pedagógico muito antes que no plano biológico e medicinal. É possível que não esteja longe o dia em que a pedagogia se envergonhe do próprio conceito de "criança com defeito". Compete aos educadores o desaparecimento das condições sociais de existência desses defeitos, ainda que o cego continue cego e o surdo continue surdo. Provavelmente não serão compreendidos aqueles que disserem que um cego é deficiente. Assim, as pessoas dirão que um cego é um cego, que um surdo é um surdo, e nada mais.

As PNEEs com limitação visual devem conviver em ambientes compartilhados com videntes. A aceitação da cegueira é uma questão social. Os videntes buscam alternativas para que as pessoas com limitação visual voltem a enxergar, pois apresentam sérias dificuldades para conviver com a limitação do outro. A inclusão das PNEEs em nossa sociedade passa pela sua aceitação, pela compreensão de que a sua limitação não as impede de fazerem parte da sociedade. Assim, o "defeito" pode ser visto como uma força para superar tal limitação. Para Vygotsky (1997, p. 125) "o meio social e sua estrutura são o fator decisivo e final de todo sistema educativo". Segundo Santarosa (1998, p.8687) a aprendizagem

“[...] não pode ser explicada exclusivamente a partir da perspectiva cognitiva/individualista, pois envolve igualmente a dimensão social e afetiva, onde o processo de interação com o objeto social desempenha um papel fundamental".

Sobre o processo de aprendizagem, Vygotsky (1984, p.117) afirma que "o bom aprendizado é 
somente aquele que adianta ao desenvolvimento". Por meio da interação com o outro, acontece a superação das limitações, a solução dos problemas. Para o autor existem dois níveis de desenvolvimento: o Nível de Desenvolvimento Real (NDR) e a Zona de Desenvolvimento Proximal (ZDP). O NDR é a conquista já consolidada pela pessoa, aquilo que aprendeu e domina sozinha; o desenvolvimento proximal, ZDP, constitui-se no que a pessoa pode fazer com a ajuda de outras pessoas (colega, professor, bibliotecário, especialista). "Aquilo que é a zona de desenvolvimento proximal hoje será o nível de desenvolvimento real amanhã, ou seja, aquilo que a criança pode fazer com assistência hoje, ela será capaz de fazer sozinha amanhã". (Vygotsky, 1984, p.98).

No processo de mediação da ZDP de Gallimore e Tharp (1993, p.222), existem vários estágios: a dependência inicial do outro/mediador (estágio l) para a realização da atividade proposta; estágio II, quando o sujeito passa a realizar as atividades sem a ajuda externa, mas ainda não demonstra total autonomia para esta realização e estágio III, quando ocorre o processo de internalização e o sujeito adquire a autonomia no uso das ferramentas. Pode-se dizer que o estágio III é aquele em que o sujeito está no seu NDR e não precisa mais do auxílio de outro mais experiente como mediador. O estágio IV, descrito pelos autores, apresenta o processo "recursividade vertical", ou seja, quando há um retorno para a ZDP, em um nível mais elevado, pois ocorreu a aprendizagem.

Para Rego (1995, p.55) a "internalização dos sistemas de signos (a linguagem, a escrita, o sistema de números) produzidos culturalmente provoca mudanças cruciais no comportamento humano". $\bigcirc$ desenvolvimento do indivíduo acontece a partir da interação com o meio social em que vive, pois é sempre mediado pelo outro, que atribui significados para a realidade. No momento em que os processos são internalizados estes começam a ocorrer sem a intermediação de outras pessoas, propiciando a autonomia.

As tecnologias, a acessibilidade e a interação com o outro são palavras-chave para o processo de mediação e de inclusão da pessoa com limitação visual no meio cultural. A busca da autonomia do sujeito passa pela relação com o outro, constituído socialmente no meio cultural, nas relações interpessoais, para ao plano intrapessoal, por meio da aprendizagem gerando o desenvolvimento, de forma que a pessoa supere as suas limitações e seja incluída na sociedade.

\section{A FORMAÇÃO DE PROFESSORES E BIBLIOTECÁ- RIOS POR MEIO DA EAD MEDIADA POR COMPUTADOR E DE AMBIENTES VIRTUAIS DE APRENDIZAGEM}

A EAD caracteriza-se pela distância entre professor e aluno, tanto geográfica como temporal, e pela postura do aluno diante do processo de aprendizagem. $O$ aluno passa a ser agente desse processo, pois, para que haja aprendizado, há muita necessidade do seu interesse e da sua ação. Na EAD, a comunicação entre alunos e professores é mediada por documentos impressos ou por alguma forma de tecnologia e pode ser materializada por meio de material de estudo impresso, de pessoas assistindo à tele-aula e documentários, de comunicação intermediada por computador, de biblioteca virtual, TV interativa, computador multimídia, videoconferência, e-mail, entre outros. Atualmente, uma boa definição para $E A D$, seria estabelecer uma rede entre pessoas e recursos utilizando as TICs para fins de aprendizagem.

A EAD significa também o desenvolvimento de atividades de ensinar e de aprender, quando educadores e aprendizes não estão presentes no mesmo espaço físico, mas podem estar conectados, interligados por tecnologias como a Internet, podendo acontecer em tempos síncronos e assíncronos. Outras tecnologias que fazem parte da educação a distância podem ser utilizadas, como o correio (o conhecido ensino por correspondência), o rádio, a televisão, o vídeo, o CD$\mathrm{ROM}$, o telefone, o fax, entre outros.

$\mathrm{Na}$ EAD deve-se ter uma preocupação com a evolução tecnológica e a evolução pedagógica, pois a experiência nessa área já mostrou que não é somente a tecnologia que garante o sucesso da EAD, mas a pedagogia, preocupada com o papel do professor e do aluno na educação a distância. Educar a distância significa saber utilizar as ferramentas das TICs não só disponibilizando materiais, mas interagindo, trocando, aprendendo em grupos, cooperando e colaborando, mudando, transformando. Apenas transferir a prática educacional presencial para o ambiente digital não significa uma EAD de qualidade, mas sim colocar uma "roupa nova" nas práticas tradicionais. 
Litwin (2001, p.13) conceitua educação a distância como uma modalidade de ensino com características específicas, "uma maneira particular de criar um espaço para gerar, promover e implementar situações em que os alunos aprendam". Para a autora, o que distingue essencialmente a educação presencial da EAD em sua modalidade é a mediatização das relações entre os professores e os alunos, significando substituir a proposta de assistência regular à aula por uma nova proposta, onde o processo de ensino e de aprendizagem se realiza mediante situações nãoconvencionais, em espaços e tempos não compartilhados.

Ramal (2001, p.15) afirma que a EAD "processa-se em um contexto de novos sujeitos, resultado das mudanças nas relações entre trabalho, cidadania e aprendizagem". Por outro lado, a informática tem o poder de transformar o conhecimento em algo que não se caracteriza como material, flexível, fluído e indefinido, provocando, dessa forma, rupturas: a interatividade, a manipulação de dados, a correlação dos saberes por meio da rede, a plurivocidade, o apagamento das fronteiras rígidas entre texto-margens e autores-leitores. Para ela, os suportes digitais e os hipertextos são, a partir de agora, "as tecnologias intelectuais de que a humanidade passará a se valer para aprender, interpretar a realidade e transformála". Portanto, a EAD terá sua legitimidade conquistada por meio de estratégias inteligentes, que, entre outras dinâmicas, compreenderão a realização de testes online, o acompanhamento personalizado, destacandose $o$ atendimento às diferenças individuais dos alunos e novos conceitos de avaliação.

Assim, a EAD envolve diversos componentes, como ensino, aprendizagem, informação, comunicação, planejamento, gerenciamento, entre outros.

\section{A Formação de Professores por meio da EAD: o Curso de Formação em Serviço de Professores em Informática na Educação Especial do PROINESP}

A utilização de AVAs para a formação de professores por meio da modalidade de EAD mediada por computador tem-se revestido de uma "função não somente pedagógica, mas social, considerando a necessidade existente de formação, principalmente no contexto nacional". (Santarosa et al., 2005, p.2).

Para atender a esse objetivo, bem como a busca de alternativas metodológicas para a formação de professores em EAD no território nacional, o Ministério da Educação (MEC), por meio da Secretaria de Educação Especial (SEESP), criou o Programa de Informática na Educação Especial (PROINESP) com o intuito de incentivar o uso pedagógico das TICs na Educação pelos alunos com necessidades educacionais especiais, por meio da disponibilização de recursos tecnológicos e qualificação de professores. Esse programa tem por objetivos: formar em serviço, via Internet, os professores de escolas públicas inclusivas municipais e estaduais e de entidades de educação especial no uso pedagógico das TICs e da acessibilidade com vistas ao desenvolvimento e à inclusão social e digital de PNEEs; auxiliar os professores na implantação, nas respectivas instituições, de atividades de uso das TICs, integradas às atividades curriculares que desenvolvem, junto aos seus alunos especiais. (Santarosa et al., 2005, p.2).

O PROINESP prevê o financiamento de equipamentos de informática para a implantação de um laboratório nas escolas que atendam PNEEs e prevê a formação de professores. É importante ressaltar que a formação de professores em serviço, por meio de um curso a distância via Internet, justifica-se pela necessidade de formação de maior número de professores, com a possibilidade de atuação simultânea junto aos alunos. Dessa forma, agiliza-se o processo de apropriação das novas tecnologias, por parte dos professores e alunos. (Santarosa et al., 2005, p.2).

Em 2008 ocorreu a VI edição do Curso de Formação em Serviço de Professores em Informática na Educação Especial, pelo Núcleo de Informática na Educação Especial (NIEE). O NIEE é um núcleo com sede na Faculdade de Educação (FACED), da Universidade Federal do Rio Grande do Sul (UFRGS), em Porto Alegre/RS. Segundo Santarosa (1997, p. 1 18), o foco das experiências no NIEE constitui-se na "busca de um novo paradigma educacional, abrindo espaços alternativos de desenvolvimento dos alunos, de modo particular, para PNEEs visando a 'Escola Virtual' como ambiente de interação/comunicação e acesso à informação". O NIEE atua tendo as seguintes metas de trabalho: desenvolver pesquisa na área de 
Informática na Educação geral e especial; desenvolver ambientes de aprendizagem computacionais (software e sites) visando ao desenvolvimento das dimensões cognitivas e sócio-afetivas no atendimento a crianças e jovens da educação geral e especial; formar recursos humanos (pesquisadores/professores) na área de Informática na Educação; socializar o conhecimento/ metodologias construídos por meio de publicações e divulgação em eventos.

Dentre as pesquisas realizadas no NIEE, Santarosa (1997, p. 134) destaca a importância da utilização de AVAs na educação: presença do diálogo/ conversação síncrona/assíncrona aluno-aluno, no contexto de aprendizagem em colaboração e interação social; dinâmica de interação na dimensão de troca/ cooperação/construção conjunta na realização das atividades em rede; apresentação de meios/ferramentas/ softwares em rede que gerem motivação intrínseca; atuação do professor como observador/interventor em oposição ao organizador/transmissor nas atividades em rede mediadas pelo professor; ênfase no desenvolvimento de processos mentais superiores em oposição à memorização/retenção de informação; incentivo à exploração/descoberta na construção de conhecimento na dimensão do construtivismo social no acesso/interação a ambientes telemáticos; ênfase na intervenção/criação de conflitos cognitivos, do ponto de vista individual, e principalmente sócio-cognitivos, do ponto de vista do grupo; incentivo a interação/ cooperação/construção no enfoque "todos-todos", além do acesso à informação disponibilizada em rede.

Diante do exposto, torna-se inevitável a oferta de novos cursos de formação para professores por meio da EAD mediada por computador em AVAs. $\bigcirc$ mesmo deve ocorrer em relação a outros profissionais, como os bibliotecários, para possibilitar a sua atualização e capacitação atuando com as PNEEs, de forma a atender as suas necessidades e melhor compreender e aceitar a diversidade de nossa sociedade.

Devido à inexistência de cursos de formação de bibliotecários no Brasil que abordem temas relacionados à acessibilidade, atendimento a usuários com necessidades especiais, entre outros, e principalmente na modalidade de educação a distância mediada por computador, surgiu a oportunidade de criar um curso com estas características que venha ao encontro dos anseios e necessidades desse profissional da informação.

\section{A Formação de Bibliotecários por meio da EAD: - BIBLIOTEC II}

O Curso BIBLIOTEC, do Departamento de Ciências da Informação (DCI), da Faculdade de Biblioteconomia e Comunicação (FABICO), da UFRGS, foi o primeiro curso em EAD, ministrado no Brasil, com ênfase na biblioteca escolar. A carga horária foi de 80 horas, realizado no período de oito de abril a 31 de maio de 2002, contando com a participação de acadêmicos de Biblioteconomia e profissionais atuantes em Bibliotecas Escolares de diversas Unidades da Federação, além do Rio Grande do Sul, Minas Gerais, Distrito Federal, Rio de Janeiro e São Paulo.

Reveste-se de grande importância o oferecimento de cursos de formação de bibliotecários na área de bibliotecas escolares e, devido à carência de disciplinas, nos cursos de Biblioteconomia, que abordem as temáticas de inclusão, acessibilidade, leiaute, uso e acesso a materiais especiais para PNEEs, entre outros.

Diante do exposto, foi realizada uma nova edição do BIBLIOTEC, no período de maio a junho de 2006, com duração de 80h, por meio da utilização do AVA TelEduc, na modalidade de EAD mediada por computador, com o objetivo de qualificar e atualizar os bibliotecários que atuam em bibliotecas escolares na rede pública e privada de ensino, que atendam PNEEs em suas unidades de informação.

Dentre os AVAs disponíveis para utilização na EAD mediada por computador, destaca-se o TelEduc, desenvolvido pelo grupo de pesquisadores do Núcleo de Informática Aplicada à Educação (NIED), da UNICAMP.

Este ambiente foi desenvolvido de forma participativa, ou seja, todas as ferramentas foram idealizadas, projetadas e depuradas segundo as necessidades relatadas pelos usuários. Com isso, ele apresenta características que diferenciam dos demais ambientes para a educação a distância, disponíveis no mercado, como a facilidade de uso por pessoas não especialistas em computação, a flexibilidade quanto a como usá-lo, e um conjunto enxuto de funcionalidades". (Carneiro, 2003, p.34).

O AVA TelEduc é um ambiente de fácil utilização e possui as ferramentas: Estrutura do Ambiente; 
Dinâmica do Curso (informações sobre a metodologia do curso); Agenda (apresentação da programação do curso); Atividades; Material de Apoio (indicação de páginas de ferramentas gratuitas para download e necessárias para a comunicação e realização de atividades pelas PNEEs); Leituras; Perguntas Freqüentes; Parada Obrigatória; Mural; Fóruns de Discussão; Batepapo; Correio (e-mail); Grupos; Perfil; Diário de Bordo; Portfólio (página individual de cada participante); Acessos (possibilita saber a freqüência de acesso dos usuários); Configurar (alteração de senha e seleção de idioma) e Intermap (visualização da interação do grupo). Estas ferramentas possibilitam que o aluno tenha autonomia para a realização das atividades propostas e possa estabelecer uma relação de comunicação com os demais componentes do grupo, sem necessitar da intervenção do professor por tempo integral.

Foram objetivos específicos do BIBLIOTEC II: qualificar profissionais que atuam em escolas e bibliotecas escolares, propiciando condições de realizar a inclusão pedagógica, social e digital dos alunos e usuários das bibliotecas escolares. Oportunizar a esses profissionais um contexto estimulante que favoreça o desenvolvimento e o intercâmbio de experiências na sua área de atuação, contribuindo para a qualidade no atendimento às PNEEs e na inclusão social, digital e pedagógica. Estimular e desenvolver habilidades de busca e uso da informação, facilitando a atualização permanente e o atendimento qualificado. Oportunizar qualificação e atualização profissional por meio da Educação a Distância mediada por computador.

oferecimento desse curso foi a oportunidade para que os profissionais buscassem uma maior atualização nos temas abordados e se sentissem competentes para atuar com as PNEEs, tornando a biblioteca um espaço de inclusão e um ambiente de aprendizagem em consonância com a escola inclusiva.

\section{METODOLOGIA DA PESQUISA}

Nesta pesquisa, buscou-se investigar como ocorre, na formação a distância em AVAs, o processo de apropriação e de interação, no uso das TICs, de professores e de bibliotecários com limitação visual. Dentre os objetivos destacam-se: propiciar a formação e a capacitação a distância de professores e bibliotecários com limitação visual, por meio de AVA; observar e acompanhar o processo de apropriação no uso das TICs, pelos sujeitos com limitação visual em AVA, por meio da formação a distância; observar e analisar como se dá o processo de interação entre si das PNEEs com limitação visual e entre elas e as pessoas com visão normal; avaliar o processo de apropriação e interação dos professores e bibliotecários com limitação visual em AVA e a inclusão social, digital e profissional.

Os sujeitos desta pesquisa são professores e bibliotecários considerados PNEEs com limitação visual, alunos do PROINESP e do BIBLIOTEC II. Para preservar a identidade dos sujeitos da pesquisa, serão utilizadas siglas. São sujeitos da pesquisa: SB: pedagoga, especialista em supervisão escolar e orientação educacional, mestre em educação, 38 anos. NO: professora, pedagoga, especialista em Planejamento Educacional, 43 anos. AL: professora e bibliotecária, especialista em Psicopedagogia, 35 anos. AM: pedagogo e bibliotecário, 42 anos.

Esta pesquisa caracteriza-se por ser qualitativa e por ser um estudo de caso. No decorrer do processo, foram aplicadas entrevistas orais semi-estruturadas, partindo de questionamentos pré-estabelecidos, e outros que surgiram ao longo da conversa, por meio do uso de ferramentas como telefone virtual (skype), correio eletrônico, entre outros. Outro instrumento aplicado teve como suporte os documentos apresentados, por meio de análise das produções do grupo, utilizando-se as ferramentas eletrônicas do ambiente TelEduc.

\section{SÍNTESE DOS RESULTADOS DA PESQUISA}

processo foi analisado no desenvolvimento dos cursos PROINESP e BIBLIOTEC $\mathrm{Il}$, por meio da participação dos sujeitos: SB, NO, AL e AM.

Em um primeiro momento, responder a este questionamento se configurou como uma situação complexa, cujo resultado final talvez não terminasse em êxito. As primeiras inserções de SB, NO e AL em um AVA ocorreram com grande dificuldade e exigiu uma dedicação muito grande por parte dos mediadores. A proposta inicial do curso era participação de um vidente acompanhando-as nos momentos em que as tecnologias não apresentavam a acessibilidade 
necessária para serem um instrumento facilitador nesse processo de inclusão em um ambiente virtual, ou mesmo quando a ausência de visão também limitava a sua participação. No entanto, a colega com visão normal que acompanharia $\mathrm{SB}$ e $\mathrm{AL}$ apresentava menos conhecimento em relação às tecnologias do que ambas e a colega de NO desistiu antes de o curso iniciar-se.

Diante dessa perspectiva e da distância física em que se encontravam formadores e professores/ alunos, do Nordeste ao extremo Sul do Brasil, SB assumiu o papel de mediadora do processo. $A L$, por conseqüência, também acreditou que seria possível e, ambas, enfrentaram as dificuldades apresentadas. $\bigcirc$ mesmo fez $\mathrm{NO}$, que sem sua colega de escola para auxiliar, encarou o desafio.

$\mathrm{SB}, \mathrm{AL}$ e $\mathrm{NO}$ demonstraram motivação para superar as dificuldades, e em nenhum momento se colocaram em uma posição de passividade ou inferioridade diante do grupo por possuírem uma limitação, e, da mesma forma, foram aceitas pelo grupo como colegas, independentemente das suas limitações sensoriais.

A condição principal para a participação em um curso na modalidade EAD e em um AVA era a apropriação das ferramentas, pois as únicas formas de comunicação estavam relacionadas ao uso do e-mail, do fórum de discussão, da ferramenta de bate-papo. Foi necessário que $\mathrm{AL}$, SB e $\mathrm{NO}$ se apropriassem das ferramentas para que pudessem interagir com o grupo. Nesse processo, quando a apropriação ocorre primeiro no nível interpessoal e depois no intrapessoal, a relação com o outro foi fundamental. Em muitas situações foi registrado o quanto as palavras de incentivo, o fato de "estar junto" mesmo que distantes fisicamente, possibilitou que elas fizessem parte de um coletivo, do grupo.

Se em relação ao uso de algumas ferramentas, em especial aquelas que não são totalmente acessíveis, $\mathrm{AL}, \mathrm{SB}$ e $\mathrm{NO}$ necessitaram do suporte das formadoras e dos colegas, e serviram de mediadoras entre si, em outras situações orientaram seus colegas e colaboraram, compartilhando do seu conhecimento e das suas experiências, principalmente em relação ao uso de tecnologia assistiva. As atividades realizadas e o desempenho de ambas foram surpreendentes, e suas produções apresentavam uma maior qualidade do que a de muitos trabalhos apresentados pelos seus colegas com limitação normal.
U uso do AVA possibilitou uma dinâmica de interação e a possibilidade da realização de atividades em rede, tanto no trabalho realizado pelos professores/ alunos, como pelos seus alunos que interagiram entre si e com outros. Foram ações que uniram de Norte a Sul o Brasil, por meio da Internet, e possibilitou que os sujeitos fossem agentes do seu processo de aprendizagem, respeitando o seu tempo e o tempo do grupo. As dificuldades foram solucionadas com o apoio do outro e a aprendizagem foi mediada, em processo de construção conjunta, que permite que o indivíduo cresça e que o seu grupo se qualifique. Também se configurou como uma possibilidade de acesso à informação, seja em formato bibliográfico ou eletrônico.

A epistemologia vygotskyana que fundamentou este estudo demonstrou que foi possível acreditar mais nas forças do que nas deficiências. Quando as tecnologias não correspondiam às expectativas, quando a limitação visual parecia que seria realmente um empecilho para o processo, o humano, a crença de que o homem pode superar todas as limitações quando acredita no seu potencial foram preponderantes. Em situações como a construção da página pessoal, por $\mathrm{SB}$, a criação das histórias narradas, mostraram que, acima de tudo, está a relação com o outro, a criatividade, O SER humano com todas as suas habilidades e potencialidades. E, a cada novo desafio, era possível amparar-se nas construções anteriores e acreditar que, se havia sido possível realizá-lo, porque não dar um passo a mais? Como em uma espiral, sempre um nível acima, apoiado por um mediador mais experiente.

E nesse processo, $\mathrm{AL}$ aceitou o desafio de participar de mais um curso, o BIBLIOTEC II. Nesse curso, $A L$ sentindo-se mais segura no uso das ferramentas, passou a desempenhar o papel de mediadora e, inclusive, auxiliou na inclusão de AM nesse novo espaço virtual. Ambos interagiram com o grupo, construíram coletivamente e sentiram-se parte integrante do grupo. No uso da ferramenta Skype - a que apresentou uma maior acessibilidade, mas infelizmente limita o número de participantes -, $\mathrm{AL}$ e AM sentiram-se plenos no uso da tecnologia. AM chega a expressar em relação ao encontro: "foi acessível, foi bom, foi humano". Dessa forma, as ferramentas aproximaram as pessoas e fizeram com que $A L$ e $A M$ sentissem desejo de expressar o seu contentamento, de compartilhar das suas experiências e de, inclusive, 
propor novas formas de uso, como: o professor interagir com os alunos e solucionar as suas dúvidas; um colega que possui a visão normal realizar solidariamente a leitura de um texto ou mesmo de um livro para uma pessoa com limitação visual, e, principalmente, permitir que ocorra o processo de comunicação.

\section{CONSIDERAÇÕES FINAIS}

A partir das análises realizadas dos processos de apropriação e de interação dos sujeitos desta pesquisa, pode-se concluir que $S B, A L, N O$ e $A M$ conseguiram apropriar-se das ferramentas e serem mediadores do processo dessa apropriação pelos seus alunos e interagiram entre eles (sujeitos), com os colegas, com os formadores e com os alunos por meio do uso das ferramentas.

Nessa perspectiva, como resultado da pesquisa, pode-se concluir que o acesso, o uso e a apropriação das ferramentas são os primeiros passos para que ocorra a inclusão em um AVA e a aprendizagem. Para os sujeitos desta pesquisa, algumas ferramentas tecnológicas já eram conhecidas, mas o uso da informática para a educação e, principalmente, a formação/qualificação a distância de professores e bibliotecários, por meio da EAD, era algo novo em suas vidas. E a apropriação dessas ferramentas ocorreu quando eles foram capazes de interagir com os seus pares e formadores, muitas vezes assumindo o papel de mediadores, sendo, como os mais experientes, suportes para o outro em um aprendizado originado a partir da ZDP, em uma relação que se caracterizou como interpessoal, onde ocorre a internalização (intrapessoal) e o sujeito demonstra o seu aprendizado e passa a ser mais experiente, em um estágio posterior, que é o seu NDR.

Nessa condição, os sujeitos foram capazes de orientar os seus alunos e produzir conjuntamente com eles. Essas produções possibilitaram que se sentissem capazes, confiantes, acreditassem em suas potencialidades. Por meio do uso das ferramentas, das TICs, foram capazes de construir, de criar, não somente entre eles, mas com alunos de outras escolas, de outros Estados do Brasil. Em um processo de inclusão no cenário educacional, pode-se dizer que foi possível concretizar a inclusão destes sujeitos como alunos, respeitando e valorizando as suas diferenças, pois conseguiram realizar as mesmas atividades propostas para todos. E mesmo que tenham sido utilizadas ferramentas diferenciadas para a criação de histórias, por exemplo, o objetivo da construção de uma narrativa em conjunto foi atingido. $\bigcirc$ foco estava no uso das ferramentas e na acessibilidade, ou na falta de, sendo necessário buscar alternativas no seu uso, e não nas limitações do sujeito.

Verificou-se que a limitação ou a "deficiência" se encontra nas ferramentas e na falta de acessibilidade. No momento em que esses instrumentos estiverem totalmente adequados, atendendo as necessidades de todos - e para que ocorra este processo faz-se necessário o desenvolvimento de mais pesquisas -, as pessoas que estiverem interagindo com o outro não perceberão que possuem necessidades especiais, como pode ser comprovado nos vários registros realizados ao longo desta pesquisa. Será um professor, um bibliotecário, um aluno, a atenção estará voltada para o SER, social, interativo e não para as suas limitações, sejam elas mentais, físicas ou sensoriais.

Também foi analisado o processo de interação, que ocorreu tanto no uso das ferramentas de comunicação e interação internas ao AVA como as externas, entre os sujeitos desta pesquisa, os seus pares, formadores e alunos. Essa relação ocorreu tanto de um para outro, como de um para muitos. Mesmo quando parecia que a falta de acessibilidade não permitiria que esse processo ocorresse, a força de vontade, o desejo e a superação foram preponderantes. A utilização do leitor de telas nas opções "ler todas as mensagens" e da tecla TAB ao longo de todo texto até encontrar a(s) última(s) mensagem(ns) postada(s), por meio de um sintentizador de voz e do teclado, são ações muito cansativas e de muita paciência. Os sujeitos demonstraram que o desejo de estar com o grupo e compartilhar com eles, expresso em comentários e registros no próprio bate-papo, serviram de estímulo para enfrentar os desafios e seguir adiante. O professor/ aluno foi competente para assumir uma postura ativa frente ao seu aprendizado e do grupo, demonstrado por meio das relações estabelecidas, das construções compartilhadas e construídas, tornando-se um ser social, interativo, enfim, sócio-interacionista.

E o processo de inclusão em um AVA foi evidenciado quando $A L$ sentiu-se encorajada a enfrentar 
um novo desafio e participar de mais um curso; $\mathrm{NO}$, a utilizar as ferramentas com seus alunos, sendo o uso da internet algo muito novo para ela; SB, a assumir o papel de mediadora e AM, a conseguir, mesmo em curso de menor duração, interagir com os seus pares e construir em conjunto com eles.

\section{REFERÊNCIAS}

CARNEIRO, M.L.F. O acoplamento tecnológico e a comunicação em rede: inventando outros domínios de aprendizagem. 2003. 161f. Tese (doutorado em informática e educação) Centro Interdisciplinar de Novas Tecnologias na Educação, Universidade Federal do Rio Grande do Sul, 2003.

GALLIMORE, R.; THARP, R. Concepción educativa en la sociedad: enseñanza, escolarización y alfabetización. In: MOLL, L.C. Vygotsky y la educación: connotaciones y aplicaciones de la psicología socio histórica en la educación. Buenos Aires: Aique Grupo Editor, 1993.

LITWIN, E. Educação a distância: temas para o debate de uma nova agenda educativa. Porto Alegre: Artmed, 2001.

RAMAL, A.C. Entre mitos e desafios. Pátio Revista Pedagógica, v.5, n. 18, p.12-16, 2001.

REGO, T.C. Vygotsky: uma perspectiva histórico cultural na educação. Petrópolis: Vozes, 1995.
Verificou-se que o acesso e uso das ferramentas e o processo de interação com os outros, entre as PNEEs com limitação visual, propiciou a inclusão em um AVA e a aprendizagem, por meio da formação e da capacitação dos professores e bibliotecários, por meio da EAD mediada por computador.

SANTAROSA, L.M.C. Comunicar para aprender, aprender para comunicar: ambientes de aprendizagem telemáticos como alternativa. Revista Integração, p.46-50, 1998.

SANTAROSA, L.M.C. Escola virtual para a educação especial: ambientes de aprendizagem telemáticos cooperativos como alternativa de desenvolvimento. Revista de Informática Educativa, v.10, nl, p.115-138, 1997.

SANTAROSA, L.; PASSERINO, L; CARNEIRO, M; GELLER, $M$. Ambientes digitais de formação de professores a distância: projeto brasileiro de informática na educação especial do MEC. Disponível em: <http://www.niee.ufrgs.br/ciiee2005/dia_23/ 001. doc $>$. Acesso em: 16 fev. 2008.

VYGOTSKY, L.S. A formação social da mente. São Paulo: Martins Fontes, 1984.

VYGOTSKY, L.S. Obras escogidas: fundamentos de defectologia. Madrid: Visor, 1997. v.5.

VYGOTSKY, L.S. Psicologia pedagógica. Porto Alegre: Artmed, 2003. 